ЏFatec

\title{
POTENCIAL DE REDUÇÃO DA PEGADA DE CARBONO E DE CUSTOS VARIÁVEIS EM EMPREENDIMENTOS DE PEQUENO PORTE: ANÁLISE DO IMPACTO DO CONSUMO DE ENERGIA ELÉTRICA EM UM SALÃO DE BELEZA DE SÃO PAULO
}

\section{POTENTIAL FOR REDUCING CARBON FOOTPRINT AND VARIABLE COSTS IN SMALL ENTERPRISES: ANALYSIS OF ENERGY CONSUMPTION OF ELECTRIC IMPACT IN A SATO PAULO SALON}

Recebido: 20/09/2015 - Aprovado: 23/10/2015 - Publicado: 29/12/2015 Processo de Avaliação: Double Blind Review

Heloisa Candia Hollnagel ${ }^{1}$

Doutorado em Ciências Biológicas (Bioquímica) pela Universidade de São Paulo

Universidade Federal de São Paulo $\underline{\text { heloisa.hollnagel@unifesp.br }}$

\author{
Paloma Akiko Onaga \\ Graduanda em Ciências Contábeis \\ UNIVERSIDADE FEDERAL DE SÃO PAULO - UNIFESP \\ paloma_onaga@hotmail.com
}
Francisca Candida Candeias de Moraes
Mestre em Gestão Empresarial.
Universidade Federal de São Paulo
Universidade São Francisco
francisca.moraes@tangramsocial.com.br

RESUMO: A contabilidade como ciência da informação tem um papel cada vez mais importante na promoção do Desenvolvimento Sustentável, pois, sua forma sistemática de registro e controle fornece dados à empresa sobre gastos e investimentos com o meio ambiente bem como a possibilidade reduzir custos e avaliar o impacto socioambiental do negócio. O presente estudo pretende colaborar com a divulgação e o conhecimento

\footnotetext{
${ }^{1}$ Autor para correspondência: UNIFESP, Rua Angélica, nº 100 - Jardim das Flores - Cidade: Osasco - SP - Brasil CEP: 06110-295.
}

REMIPE- Revista de Micro e Pequenas Empresas e Empreendedorismo da Fatec Osasco 
de metodologias para o cálculo de emissões de carbono em empreendimentos de pequeno porte, com ênfase no consumo de energia elétrica, tendo por base um salão de beleza. A pesquisa, exploratória, aplicada e descritiva, utilizou pesquisa telematizada e observações in loco para o estudo de caso, com um inventário dos equipamentos eletroeletrônicos e entrevista não estruturada da gestora/ proprietária do salão para identificação de aspectos subjetivos e detalhamento complementar. Recentemente o Brasil assumiu o compromisso de reduzir em $37 \%$ as emissões de gases causadores do efeito estufa entre 2005 e 2025 e em $43 \%$ até 2030 . Contudo, o cálculo da pegada de carbono nem sempre compatível com as prioridades e realidade das micro e pequenas empresas, o que justifica este estudo, que apresenta ideias preliminares para contribuir na minimização dos impactos ambientais decorrentes das operações com equipamentos que utilizam esse recurso natural. Os resultados apontam a possibilidade de redução nas emissões de $\mathrm{CO}_{2}$ com pequenas intervenções, por exemplo, no projeto de iluminação do ambiente, com a substituição de lâmpadas incandescentes por LED, possibilidade para a criação de políticas públicas de incentivo ao consumo sustentável no segmento. Considerando que um reforço para a responsabilidade ambiental corporativa é a possibilidade de ter benefícios tangíveis, tais como aumento do lucro ou da redução de custo, o presente trabalho mostra uma maneira simples de ter esse retorno e ao mesmo tempo colaborar para atingir tanto as metas da PEMC e PNBMC quanto o compromisso de Contribuições Nacionalmente Determinadas Pretendidas brasileiras da COP21.

PALAVRAS-CHAVE: Desenvolvimento sustentável; Pegada de Carbono; pequenas unidades de negócio; salões de beleza; contabilidade ambiental.

ABSTRACT: Accounting as an information science has increasingly important role in the promotion of Sustainable Development, because its systematic registration and control provides data about spending and investment with the environment as well as a possibility to minimize expenses or costs and assess the impact social and environmental business of the organization. The present study intends to collaborate with the development of methodologies of carbon emissions calculation in Small-sized Enterprises, with emphasis on the consumption of electricity, on the basis of a Beauty Salon analysis. Using exploratory, descriptive and applied research, the techniques used were direct observation, for the inventory of electronics equipment and notstructured interview of the owner for identification of subjective aspects and gather further details. Recently, Brazil has committed to reduce by $37 \%$ the emissions of greenhouse gases between 2005 and 2025 and by 43\% in 2030. However, carbon footprint calculation is not always compatible with priorities and reality of small and micro companies, justifying this study which presents preliminary ideas in order to contribute to the minimization of environmental impacts arising from operations with require electrical energy to drive processes and equipment. Results indicate the possibility of reduction in $\mathrm{CO}_{2}$ emissions with small interventions for example, modifying the lighting design, with the use of light-emitting diodes (LED) in replacement of incandescent bulbs, opening possibilities of creation of public policies for sustainable consumption in this economic segment. Considering that profit increasing and cost reduction are reinforcement for Corporate Environmental Responsibility, the present study shows a simple way to collaborate on the achievement

REMIPE- Revista de Micro e Pequenas Empresas e Empreendedorismo da Fatec Osasco

V. 1, N², jul.-dez. 2015. 
of São Paulo State Climate Change Policy and Brazilian National Plan on Climate Change goals as well as the Intended Nationally Determined Contributions of COP21.

KEY WORDS: Sustainable development; carbon footprint; small business units; beauty salon; environmental accounting.

\section{INTRODUÇÃO}

O processo de mudanças climáticas, principalmente as devidas ao aquecimento global induzido pela atividade humana, tem tido cada vez maior grau de preocupação por parte de acadêmicos, organizações e nações, pois constitui uma importante questão socioambiental não apenas pela complexidade dos processos nelas envolvidos, mas também considerando a magnitude dos impactos dela decorrentes.

Nesse contexto, as ações para reduzir as emissões de gases de efeito estufa (GEE) produzidos por atividades antropogênicas têm papel central e desafiam todos os setores da sociedade visto que dependem da realização de mudanças tecnológicas e comportamentais.

É de conhecimento amplo que as principais fontes responsáveis pelo aumento da concentração de GEE na atmosfera são: a queima de combustíveis fósseis, a mudança do uso do solo e a produção e consumo de energia elétrica, principalmente de fontes não renováveis, sendo o $\mathrm{CO}_{2} \mathrm{o}$ principal gás estufa produzido.

Pesquisa recente da Empresa de Pesquisa Energética, vinculada ao Ministério de Minas e Energia (EPE, 2014) mostra um aumento da penetração da energia elétrica no quinquênio 2009-2013, já que a população aumentou, em média, 0,9\% ao ano, enquanto que o consumo per capita apresentou crescimento médio de $3,8 \%$ ao ano no período; o aumento de consumo nas residências, comércios e serviços aumentou de $43 \%$ para 45\%, considerando os valores registrados em 2012.

Embora os dados sejam conhecidos, assim como as consequências do uso não sustentável dos recursos, no contexto capitalista muitas vezes as opções de investimento são por aquelas que oferecem menor custo ou maior retorno, independente de seu efeito no futuro do planeta.

Esta pesquisa parte do pressuposto da tomada de decisão de reduzir o consumo a partir da percepção da relevância de suas ações na economia de recursos financeiros,

REMIPE- Revista de Micro e Pequenas Empresas e Empreendedorismo da Fatec Osasco 
entendida no contexto capitalista, no qual o comportamento de consumo é função da prática social, no escopo definido por Reckwitz (2002, p. 249):

[...] um tipo de comportamento rotinizado que consiste de vários elementos, interligados uns aos outros: formas de atividades corporais, formas de atividades mentais, "coisas" e seu uso, conhecimento prévio na forma de entendimento, know-how, estados de emoção e conhecimento motivacional.

Dessa forma, parte-se do pressuposto geral de que o consumo ocorre no âmbito de práticas incorporadas, como definido na Teoria da Prática:

[...] processo pelo qual os agentes se engajam na apropriação e apreciação, seja com propósitos utilitaristas, expressivos ou contemplativos, de bens, serviços, desempenhos, informação ou ambiência, seja comprado ou não. (WARDE, 2005, p. 137)

No contexto econômico capitalista, o lucro é a principal intenção dos empresários; assim, mudar suas práticas se torna possível na medida em que percebe a possibilidade de recompensa - neste caso financeira. A argumentação em torno da responsabilidade ambiental, do consumo consciente e outros temas relacionados à tomada de decisão com base na reflexão consciente não tem se demonstrado integralmente efetiva, se não apresentar recompensas significativas do ponto de vista do lucro ou da redução de custo.

No Brasil, se destaca o planejamento de curto prazo nos empreendimentos; assim, a possibilidade de pagar menos inicialmente é vista como "levar vantagem", em especial nas micro e pequenas empresas, nas quais a formação educacional nem sempre é adequada aos negócios propostos. Esse fato se reflete no caso estudado - salões de beleza - onde a iluminação não é percebida como de grande influência na percepção do resultado pelo cliente, sendo um elemento complementar da instalação física - levando ao comportamento de compra de lâmpadas com menor custo, sem considerar o impacto do custo do consumo ao longo do tempo.

Este estudo, que visa identificar os benefícios financeiros para o empreendedor do segmento de serviços de beleza, pela substituição de lâmpadas incandescentes por outras de maior eficiência energética LEDs (light-emitting diodes), apresenta alto grau de relevância, na medida em que a recompensa financeira de forma significativa na 
troca possibilita o entendimento claro de seus benefícios financeiros e, consequentemente, ambientais. Por outro lado, normalmente os estudos sobre o segmento apresentam os problemas e propostas visando à redução do consumo de energia elétrica focando o uso dos equipamentos, raramente considerando a questão da iluminação, que, conforme identificado, apresenta alto grau potencial de diminuição desse recurso natural.

\section{REFERENCIAL TEÓRICO}

\subsection{DESENVOLVIMENTO E MUDANÇAS CLIMÁTICAS}

Desde o início dos anos 90, vários países estabeleceram programas nacionais prevenção ao aquecimento global. Em dezembro de 1997, o Protocolo de Quioto estabeleceu metas de redução de emissão de gases de efeito estufa e mecanismos adicionais de implementação para que estas metas fossem atingidas, tais como estimular projetos nos países em desenvolvimento que possibilitem a redução das emissões de Gases de Efeito Estufa (GEEs) ou racionalização do uso da energia além de sequestro de carbono por florestamento e reflorestamento entre outros (LOPES, 2002).

A Convenção-Quadro da ONU sobre Mudança do Clima, aberta em 1992 e ratificada em 2012, destaca o compromisso dos países signatários em formular e programar políticas para as mudanças climáticas. Os relatórios do Painel Intergovernamental de Mudanças Climáticas (Intergovernamental Panel Climate Change - IPCC) têm sido objeto de apreciação de acadêmicos e leigos, pois, a divulgação pelas mídias de alguns de seus dados e cenários futuros quanto ao aumento dos Gases de Efeito Estufa (GEE) e o aquecimento global, caso medidas não fossem tomadas pelos governos e sociedade transformou-se em uma questão de responsabilidade global compartilhada.

Segundo o Plano Nacional Brasileiro de Mudanças Climáticas (PNBMC, 2008), a mudança do clima é o resultado de um processo crescente de acúmulo de gases de efeito estufa (GEE) na atmosfera, em curso desde a Revolução Industrial. Contudo, a influência da atividade humana sobre o clima é complexa, onde os fatores: consumo, tipo de energia produzida e utilizada, habitações em espaço urbano ou rural, estoques de capital per capita de um país, pirâmide etária e, até mesmo aspectos culturais, tem

REMIPE- Revista de Micro e Pequenas Empresas e Empreendedorismo da Fatec Osasco 
relação com a igualdade de direitos e oportunidades desfrutada por mulheres e homens (JACOBI et al., 2011).

Consequentemente, a Lei Federal No. 12.187/2009 (que institui a Política Nacional sobre Mudança do Clima) objetiva em linhas gerais, no país: a) redução das emissões antrópicas de gases de efeito estufa em relação às suas diferentes fontes; $b$ ) fortalecimento das remoções antrópicas por sumidouros de gases de efeito estufa no território nacional; e c) implementação de medidas para promover a adaptação às mudanças do clima. No artigo $12^{\circ}$. da Lei $N^{\circ}$. 12.184/2009 é estabelecido o compromisso voluntário do Brasil de reduzir entre 36,1\% e 38,9\% suas emissões projetadas até 2020 em relação ao $2^{\circ}$ Inventário Brasileiro, de 2010.

O governo brasileiro anunciou recentemente sua posição quanto ao novo Acordo sobre Mudança do Clima a ser adotado no âmbito da Conferência das Partes (COP21) da Convenção-Quadro das Nações Unidas, em Paris, assumindo compromisso de agir efetivamente para combater o aquecimento global, no âmbito das denominadas INDC (Intended Nationally Determined Contributions ou Contribuições Nacionalmente Determinadas Pretendidas). O compromisso voluntário brasileiro é de reduzir em 37\% as emissões de gases causadores do efeito estufa entre 2005 e 2025 e em $43 \%$ até 2030.

A PNMC foi associada a diversas outras políticas estaduais, visando refletir as especificidades regionais e realidades locais. No Estado de São Paulo, a Lei $\mathrm{N}^{\mathrm{o}}$ 13.798/2009, que instituiu a política estadual sobre o tema, estabeleceu metas de redução global das emissões de $\mathrm{CO}_{2}$ em $20 \%$ até 2020 .

As críticas do setor produtivo às metas fazem considerações sobre o cenário econômico recessivo, a sobrecarga tributária, sistemas trabalhistas e previdenciários inadequados mas com uma responsabilidade ambiental de nações desenvolvidas, pontuando que os custos de intervenções e melhorias para que os processos apresentem uma menor pegada de carbono são altos.

Entretanto, o presente trabalho mostra uma estratégia viável para pequenos empreendimentos com alta capilaridade no cenário econômico nacional contribuam para a redução das emissões de gases de efeito estufa, sendo o retorno financeiro um contraponto ao investimento inicial necessário.

REMIPE- Revista de Micro e Pequenas Empresas e Empreendedorismo da Fatec Osasco 


\subsection{EMPREENDEDORISMO NO BRASIL}

Anualmente, o SEBRAE - Serviço Brasileiro de Apoio às Micro e Pequenas Empresas- publica os dados da pesquisa GEM Brasil - Global Entrepreneurship Monitor (GEM) - realizada no país em parceria com o Instituto Brasileiro de Qualidade e Produtividade (IBQP). Segundo dados de 2014, a taxa total de empreendedorismo no Brasil atingiu um recorde, desde seu início: três em cada dez brasileiros entre 18 e 64 anos são proprietários ou estão envolvidos com a criação de um negócio próprio., tendo passado nos últimos 10 anos, de $23 \%$ para $34,5 \%$ (conforme tabela 1 a seguir), sendo a metade de empreendedores novos - com menos de três anos e meio de atividade (GEM, 2015).

TABELA 1 - Taxas de empreendedorismo segundo estágio dos empreendimentos - Brasil - 2014, considerando o Percentual da população de 18-64 anos.

\begin{tabular}{|c|c|}
\hline $\begin{array}{c}\text { ESTÁGIO DO } \\
\text { EMPREENDEDORISMO }\end{array}$ & rasil \\
\hline Empreendedores iniciais & 7,2 \\
\hline Empreendedores &, 7 \\
\hline Empreendedores Novos & 3,8 \\
\hline Empreendedores Estabelecidos & 7,5 \\
\hline Taxa total de empreendedores & 4,5 \\
\hline
\end{tabular}

O empreendedorismo no país representa grandes oportunidades no segmento de beleza, não apenas na geração de empregos, mas também na redução do consumo de recursos naturais nos salões de beleza, notadamente de água e energia elétrica e, consequentemente, de custos para operação do negócio. Dados da Agência Brasil, de abril de 2015, apresentam inflação de $60,42 \%$ no período de 12 meses na energia elétrica e, considerando o aumento de custos para fornecimento desse insumo e o aumento anual exponencial do segmento, o estudo dessa variável e a apresentação de alternativas de redução podem significar a diferença entre o fechamento ou a continuidade de tais empreendimentos. 
A energia elétrica no Brasil teve sucessivos aumentos ao longo dos anos e, que, além do cancelamento da redução artificial realizada anteriormente pelo governo advinda do financiamento público da Conta de Desenvolvimento Energético (CDE), que representa 35\% do valor total, que apresentou aumento de $1.013 \%$ entre 2014 e 2015 estudos mostram que esse custo tem tendência de aumento, em especial com a adoção das bandeiras tarifárias, que corresponde a 16,3\% do montante da conta (O POVO ON LINE, 2015). Em contraponto aos produtos industrializados na China, EUA, Japão e Europa, os bens e serviços produzidos no país tendem a ficar cada vez mais caro, em razão do aumento da energia elétrica. Em setores como de serviços de beleza prestados diretamente ao consumidor - salões de beleza - como o analisado no estudo, esse componente apresenta grande impacto; nos custos fixos, como iluminação, qualquer alteração que diminua o consumo torna-se capaz de gerar um diferencial nos preços e, consequentemente, na continuidade do negócio.

\subsection{MERCADO DE BELEZA}

De acordo com a pesquisa de orçamento familiar (PFO) do IBGE (2010), no gasto médio das famílias em situação urbana ( $\mathrm{R} \$ 2.303,56)$, cerca de 1,2\% correspondem a Serviços pessoais, que engloba despesas com cabeleireiro, manicuro e pedicuro, consertos de artigos pessoais (sapateiro, relojoeiro, chaveiro, etc.) e "outras" (depilação, maquiagem, esteticista e demais despesas com serviços similares). Nessa classificação, apenas $\mathrm{R} \$ 0,49$ é relativo a consertos de artigos pessoais; os demais correspondem a serviços de cabeleireiro ( $\mathrm{R} \$ 17,51)$, manicuro e pedicuro $(\mathrm{R} \$ 6,43)$ e outras ( $\mathrm{R} \$ 3,28)$, totalizando $1,0 \%$ do gasto mensal familiar.

Segundo dados do SEBRAE (ABIHPEC, 2015), os salões de beleza correspondem a $21 \%$ do segmento de higiene pessoal e beleza, como demonstra a tabela 2:

TABELA 2. Empregos no setor de higiene e beleza no Brasil.

\begin{tabular}{|c|c|c|c|c|}
\hline \multicolumn{5}{|c|}{ OPORTUNIDADE DE TRABALHO ('000) } \\
\hline & 994 & 014 & $\begin{array}{c}\% \\
\text { Cresc. } 20 \text { anos }\end{array}$ & $\begin{array}{c}\% \text { Cresc. } \\
\text { Médio } 20 \text { anos }\end{array}$ \\
\hline Indústria & 0.1 & 26,0 & 318,6 & 7,4 \\
\hline Centros de & & & N.A.* & N.A.* \\
\hline
\end{tabular}

REMIPE- Revista de Micro e Pequenas Empresas e Empreendedorismo da Fatec Osasco 


\begin{tabular}{lccccc}
\hline \multicolumn{2}{c}{ distribuição } & & 5,0 & & \\
& Franquia & & & 1724, & 15,6 \\
Consultora & 1,0 & 00,7 & 8 & 694,8 & 10,9 \\
\multirow{2}{*}{ venda direta } & 10,0 & 053,6 & 108,1 & 3,7 \\
beleza & Salões de & 79,0 & 205,0 & 397,3 & 8,4 \\
\hline
\end{tabular}

* N.A. $=$ Não avaliado

Fonte: Panorama do Setor (ABIHPEC, 2015)

Neste segmento exponencialmente crescente, os profissionais cabeleireiros que atuam como MEI (microempreendedor individual) ME (microempresa), EPP (empresa de pequeno porte) cresceram quase $400 \%$ em 19 anos, como demonstra a tabela 3 a seguir:

TABELA 3. Serviços de Beleza no Brasil - Cabeleireiros MEI, ME e EPP.

\begin{tabular}{|c|c|c|c|c|c|c|c|}
\hline & Enquadramento & 009 & 010 & 011 & 012 & 013 & 014 \\
\hline individual & MEI - microempreendedor & & 9.071 & 125.866 & 193.822 & 59.120 & 49.864 \\
\hline & $\mathrm{ME}$ - microempresa & 5.923 & 9.866 & 2.138 & 4.467 & & \\
\hline porte & EPP- empresa de pequeno & .009 & .010 & 2.011 & .012 & & \\
\hline
\end{tabular}

(*) Dados não disponíveis

Fonte: Adaptado de Panorama do Setor (ABIHPEC, 2015)

Segundo o SEBRAE, entre abril de 2014 e abril de 2015 houve um aumento de $15,5 \%$ na procura de pequenos empreendedores por soluções que reduzam o consumo de energia em seus negócios, tendo sido identificada uma redução de $20 \%$ no consumo de energia e de $82 \%$ de redução na conta de luz após implantar ações do programa de apoio à inovação e sustentabilidade (Sebraetec; in Brasil, 2015.).

Em salões de beleza, um dos grandes desafios é a precificação, pois, como não é tão simples calcular o valor de um serviço sem possuir bases sólidas de quanto ele custa para ser executado e análise de variáveis subjetivas. O consumo de energia elétrica nesse tipo de estabelecimento é um dos elementos que mais consomem as entradas de caixa, sendo apontado por especialistas como um dos fatores que mais afetam o custo 
variável do salão, na medida em que está diretamente associado ao serviço prestado (MENDES, s.d.). No entanto, a iluminação deve ser considerada como um custo fixo, na medida em que a redução das lâmpadas acesas nesse tipo de empreendimento afeta, diretamente, a percepção do serviço, pois trata-se de um componente comunicativo. Pompermayer (2004) pressupõe que a administração de custos tem como objetivo principal a elevação dos lucros e a estabilidade no mercado, por meio das informações coletadas na apuração de cursos em uma análise ampliada.

A iluminação na percepção da beleza é um recurso altamente utilizado nos instrumentos midiáticos para a venda de produtos com a finalidade de aumentar os padrões de beleza, como ressalta Miranda (2010), ao abordar a apresentação de um famoso produto de beleza:

Ela abre o produto e uma iluminação de fundo destaca seu rosto. A mulher muda o semblante e sorri discretamente. $\mathrm{O}$ ar de preocupação desaparece dando lugar a uma sensação de satisfação com a pele. Ela olha novamente para o espelho e sorri com contentamento.

Embora pesquisa desenvolvida por Santos, Costa e Cardoso (2008) apresente a iluminação como um dos itens de menor importância nos cenários construídos na prestação de serviços de beleza, a mesma pesquisa demonstra que esse elemento é fundamental na análise perceptiva do item mais considerado (higiene e limpeza). A iluminação permite perceber mais cores (QUEIROZ NETO, 2010), em especial da pele, maquiagem e coloração dos cabelos, assim como induz à sensação de limpeza (BLESSA, 2006).

Os dados de crescimento do setor demonstram o destacado por Ribas e Caleiro (2012), de que as pessoas, na sociedade atual, buscam construir sua identidade em torno de padrões estéticos socialmente admirados, muitas vezes abrindo mão de outras despesas realmente necessárias.

Dessa forma, os salões de beleza, comum em qualquer ponto do país, independente do grau de desenvolvimento econômico da localidade, necessitam de pesquisas visando analisar sua contribuição no consumo de recursos naturais, na medida em que segundo estudo realizado por Andrade e colaboradores (2013), as atividades desenvolvidas nos salões de beleza deveriam ser tratadas no âmbito de Sistemas de 
Gestão Ambiental (SGA), na medida em que "são grandes vilões da preservação ambiental".

\section{ESTUDO DE CASO}

\subsection{DIAGNÓSTICO DA SITUAÇÃO-PROBLEMA}

O salão alvo do estudo é situado no município de São Bernardo do Campo, pertencente à região metropolitana de São Paulo, com IDHM Geral de 0,805, IDHM-R (Renda) de 0,807, IDHM-L (Longevidade) de 0,861 e IDHM-E (Educação) de 0,752², ocupando a $14^{\mathrm{a}}$ posição dentre os municípios paulistas e $28^{\mathrm{a}}$ no país, conforme o Atlas do Desenvolvimento Humano no Brasil (2015). Saliente-se que desde 1991, as condições desse município melhoraram substancialmente, na medida em que nesse ano o IDHM era de 0,642, passando para 0,740 em 2000, segundo dados do IBGE (2015), a partir das informações do PNUD (2013).

A tabela 4 a seguir apresenta o consumo estimado do salão de beleza foco do estudo, considerando os equipamentos atualmente utilizados e o tempo de utilização dos mesmos:

TABELA 4 - Cálculo de consumo de energia elétrica no salão de beleza investigado.

\begin{tabular}{lcccccc}
\hline \multicolumn{1}{c}{ Item } & Quantidade & $\begin{array}{c}\text { Potência } \\
(\mathbf{W})\end{array}$ & $\begin{array}{c}\text { Dias } \\
(\mathbf{2 0 1 3})\end{array}$ & Horas/dia & $\begin{array}{c}\text { Horas } \\
\text { totais }\end{array}$ & kWh \\
\hline Secador & 1 & 2000 & 304 & variável & $1.762,5$ & 3.225 .000 \\
$\begin{array}{l}\text { Lâmpada } \\
\text { incandescente }\end{array}$ & 5 & 100 & 304 & 10 & 15.200 & 1.520 .000 \\
Geladeira & 1 & 35 & 365 & 24 & 8.760 & 306.600 \\
Microondas & 1 & 1700 & 304 & 1 & 304 & 516.800 \\
Ventilador & 1 & 90 & 176 & 10 & 1.760 & 158.400 \\
Ventilador & 1 & 90 & 176 & 10 & 1.760 & 158.400 \\
Televisão & 1 & 290 & 304 & 10 & 3.040 & 881.600 \\
TOTAL & & & & & & 6.766 .800 \\
\hline
\end{tabular}

*variável de acordo com os dias da semana, explicado posteriormente por item.

Fonte: Elaboração própria a partir de informações disponíveis na internet.

Como as emissões de carbono não podem ser medidas, são inferidas a partir de dados de acordo com normas como o PAS 2050 (2011)- Especificação para monitoramento e relatório de gases poluentes de produtos e serviços, onde normalmente

2 O Índice de Desenvolvimento Humano (IDH) é elaborado pelo Programa das Nações Unidas para o Desenvolvimento (PNUD), com índice que varia de zero até 1, sendo considerado: Muito Alto, de 0,800 a 1; Alto, de 0,700 a 0,799; Médio de 0,600 a 0,699; Baixo de 0,500 a 0,599 e Muito Baixo de 0,000 a 0,499.

REMIPE- Revista de Micro e Pequenas Empresas e Empreendedorismo da Fatec Osasco 
são avaliados o consumo de energia elétrica por lâmpadas (iluminação) e equipamentos. Os chamados Fatores de Emissão são aqueles relacionados à emissão de GEE, a um nível de atividade ou a quantidade de um determinado produto ou serviço: por exemplo, toneladas de combustível consumido, energia utilizada ou unidades de um produto. Por exemplo, o fator de emissão mais utilizado para se medir eletricidade é "tCO2eq/megawatt-hour", conforme o Ministério da Ciência, Tecnologia e Inovação do Brasil (2015).

Foram considerados como parâmetros para a contabilização para estimativa do consumo de energia elétrica do ano de 2013 na elaboração da Tabela 5, o total de 26,10 dias úteis/mês, estabelecidos a partir dos seguintes critérios:

- $\quad 365$ dias por ano - equivalentes a 26,10 dias úteis/mês, em razão de anos bissextos;

- Excluídos 14 feriados, calculados segundo o calendário oficial brasileiro (12 feriados oficiais $+3^{\mathrm{a}}$ feira de Carnaval) + Aniversário da cidade.

- Eliminação de 52 segundas-feiras no ano, em razão do descanso semanal da equipe;

- Dias de funcionamento do salão: terça a domingo, das $9 \mathrm{~h}$ às $19 \mathrm{~h}$.

- Utilização relativa de cada item eletroeletrônico considerado significativo na unidade de negócio avaliada, com as ponderações descritas anteriormente.

- Número de unidades do equipamento, potência e horas totais de uso ao longo de 2013, conforme descrito na tabela a seguir. 
TABELA 5. Estimativa de uso dos equipamentos no salão objeto da pesquisa.

\begin{tabular}{|c|c|}
\hline Equipamento & Características do uso \\
\hline Secador & $\begin{array}{l}\text { Sextas e sábados: } 1 \text { cliente por hora, } 1 / 2 \text { hora de } \\
\text { funcionamento por cliente } \\
\text { Terças e quartas: } 25 \% \text { do tempo das sextas e sábados } \\
\text { Quintas e domingos: } 50 \% \text { do tempo de secador das } \\
\text { sextas e sábados; descontando feriados e segundas } \\
\text { feiras }\end{array}$ \\
\hline Chuveiro para lavagem de cabelo & $\begin{array}{l}\text { Sextas e sábados, } 3 \text { horas por dia } \\
\text { Quintas e domingos: } 2 \text { horas por dia } \\
\text { Terças e quintas: } 1 \text { hora por dia; descontando feriados. }\end{array}$ \\
\hline Ventilador & Horário de funcionamento do salão, de outubro a abril \\
\hline Lâmpadas e televisão & Horário de funcionamento do salão *. \\
\hline Geladeira & 365 dias no ano 24 horas por dia \\
\hline Microondas & 1 hora por dia, descontando feriados e segundas \\
\hline
\end{tabular}

\subsection{POTENCIAIS SOLUÇÕES PARA REDUÇÃO DOS INSUMOS E CUSTO}

A incorporação da variável ambiental na formulação de estratégicas empresariais é uma realidade para as organizações, em função da percepção de que, em um futuro breve, os negócios poluidores perderão competitividade e $\mathrm{o}$ comprometimento ambiental será um limitador das atividades econômicas (BARBIERI, 2007). Segundo este autor, na abordagem estratégica gerencial, as questões ambientais e as soluções conduzidas são percebidas como oportunidades para obtenção de vantagem competitiva.

No início dos anos 2000, uma pesquisa realizada pelo Instituto Ethos (2003) nos mercados emergentes mostrou que muitas empresas se beneficiavam por adotar iniciativas que aliavam progresso ao desenvolvimento sustentável e que para pequenas e médias empresas nacionais, a principal vantagem seria a redução de custos.

De acordo com o SEBRAE (2015), os principais impactos ambientais das atividades em um salão de beleza ocorrem no uso da água e energia elétrica; visando a economia, vários salões de maior porte buscaram, nos últimos anos, alternativas para a redução de tais custos, adotando iniciativas direcionadas à implantação do atualmente denominado "salão verde", como as apresentadas na tabela 6 a seguir: 
TABELA 6. Exemplos de alternativas ambientalmente sustentáveis em salões de beleza.

\begin{tabular}{|c|c|}
\hline Salão - UF & Iniciativa \\
\hline Laces and Hair - SP & $\begin{array}{l}\text { Uso de produtos orgânicos e artesanais e equipamento italiano que } \\
\text { dispensa a utilização de papel-alumínio no reflexo (redução de lixo). }\end{array}$ \\
\hline $\begin{array}{l}\text { Studio Charles Santos e } \\
\text { Vivi Guillaume - RJ }\end{array}$ & $\begin{array}{l}\text { Uso de madeira reciclada, iluminação com lâmpadas LED (maior } \\
\text { durabiilidade e menor consumo), coleta de lixo seletiva, direcionada para } \\
\text { cooperativa de catadores e uso de ecobags recicladas }\end{array}$ \\
\hline L'Officiel III - SP & $\begin{array}{l}\text { Sistema segmentado de iluminação e uso de lâmpadas que emitem menos } \\
\text { calor; troca do de sistema de aquecimento de água - aquecedores } \\
\text { automáticos a gás. }\end{array}$ \\
\hline $\begin{array}{l}\text { Rede Werner Coiffeur - } \\
\text { RJ }\end{array}$ & $\begin{array}{l}\text { Todas as franquias têm sensores de energia nos banheiros, na copa, no } \\
\text { estoque e na parte administrativa, com redução e } 15 \% \text { dos gastos com } \\
\text { eletricidade. }\end{array}$ \\
\hline Stylo Hair - PR & $\begin{array}{l}\text { Lavatórios com sistema de pressão, modelo de torneiras que interrompe o } \\
\text { fluxo automaticamente, separação do lixo e destinação dos resíduos sólidos } \\
\text { para entidade de catadores. }\end{array}$ \\
\hline Jean Yves Coiffure - RJ & Coleta seletiva, ecobags para embalagem dos produtos vendidos e uso de \\
\hline
\end{tabular}

Fonte: Green Nation (2015).

O SEBRAE promoveu em 2014 no Rio Grande do Norte para empreendedores um evento do Projeto Saúde e Bem-estar, que visa divulgar práticas de sustentabilidade neste segmento com duas abordagens:

- redução do consumo de energia elétrica: como a utilização de energias alternativas e técnicas para reduzir o consumo de energia pelos equipamentos.

- aumento do bem-estar do cliente: por meio da alteração de layout nos salões, modificando a disposição de equipamentos de acordo com o espaço, visando à circulação de ar, temperatura e luminosidade.

Uma as propostas do projeto é fazer um "planejamento visual", a partir do desenvolvimento de peças gráficas para a consolidação da imagem da empresa, gerando credibilidade perante o consumidor, pois o SEBRAE (2015) acredita que "As pessoas gostam de usufruir de locais que visam à preservação. $O$ meio ambiente é essencial para a vida das pessoas e do negócio".

\section{METODOLOGIA}

Esta investigação é exploratória e aplicada, visto que a partir dela serão gerados conhecimentos que servirão como base para novos estudos e tomadas de decisão. Quanto às características, é classificada como descritiva, pois, tem o propósito de analisar fatos ou fenômenos em sua natureza e características, procurando observar, registrar e analisar suas relações, conexões e interferências (MICHEL, 2005)

REMIPE- Revista de Micro e Pequenas Empresas e Empreendedorismo da Fatec Osasco 
Segundo os procedimentos técnicos, tem-se, inicialmente, a pesquisa de campo, com um estudo de caso, fundamentada em observações, entrevista não estruturada da gestora/ proprietária do salão bem como uma sustentação teórica que orienta o processo de inventário da produção de GEE em unidades de negócio. O objeto de estudo foi quantificar as emissões de $\mathrm{CO}_{2}$ e emitidas a partir do consumo de energia elétrica para iluminação e utilização de considerando os equipamentos eletroeletrônicos ao longo de 2013 e obter quantificar as emissões de GEE gerados de acordo com o estabelecido no GHG Protocol Brasil. Para complementar as análises, foi realizada a pesquisa telematizada. Cabe destacar que a proprietária do estabelecimento não sabia responder ou preferiu não responder foram pesquisadas na Internet e seus valores estimados.

Para o cálculo das emissões de $\mathrm{CO}_{2}$ o fator de produção de Energia Elétrica no Brasil (= 0,11 kgCO2e/kWh) foi obtido do Ministério do Meio Ambiente, cujos dados são apresentados a seguir.

Os valores financeiros foram obtidos a partir do valor da tarifa residencial aprovada pela ANEEL - Agência Nacional de Energia Elétrica para a empresa ELETROPAULO (Eletropaulo Metropolitana Eletricidade de São Paulo S/A), fornecedora desses serviços no Estado de São Paulo, com vigência para o período de 04/07/2015 a 03/07/2016: foi utilizada a tarifa residencial para o consumo mensal superior a $220 \mathrm{kWh}(\mathrm{R} \$$ 0,43611), conforme a ANEEL (Agência Nacional de Energia Elétrica), considerando que grande parte desses profissionais atua em suas próprias residências e/ou não formalizam a mudança de classificação na empresa fornecedora.

Para mensuração da durabilidade foram utilizados os dados de estudos da empresa AOD Brazil, fabricante de lâmpadas LED desde 2014, atuante no Brasil desde 1991.

\section{RESULTADOS}

\subsection{POTENCIAL REDUÇÃO DE CONSUMO COM A TROCA DAS LÂMPADAS}

A tabela 7 a seguir apresenta os dados relativos ao consumo de energia elétrica do salão de beleza foco do estudo, considerando as lâmpadas atuais (incandescentes) e 
as LEDs, considerando sua utilização conforme as estimativas definidas (uso por 10 horas por dia durante 313 dias por ano). Para o cálculo da quantidade de emissões em cada tipo de lâmpada foi utilizada a fórmula descrita na própria tabela.

TABELA 7. Consumo de energia elétrica com lâmpadas incandescentes.

\begin{tabular}{lcccccc}
\hline $\begin{array}{l}\text { Tipo de } \\
\text { lâmpada }\end{array}$ & $\begin{array}{l}\text { Quantidade } \\
\text { A }\end{array}$ & $\begin{array}{l}\text { Potência } \\
\text { (W) B }\end{array}$ & $\begin{array}{l}\text { Dias } \\
(\mathbf{2 0 1 3 )} \mathbf{C}\end{array}$ & $\begin{array}{l}\text { Horas/dia } \\
\mathbf{D}\end{array}$ & $\begin{array}{l}\text { Horas/ano } \\
\mathbf{E}=\mathbf{A} * \mathbf{C} * \mathbf{D}\end{array}$ & $\begin{array}{l}\mathbf{k W h} / \mathbf{a n o} \\
\mathbf{F}=\mathbf{B} * \mathbf{E}\end{array}$ \\
\hline Incandescente & 5 & 100 & 313 & 10 & 15.650 & 1.565 \\
LEDS & 5 & 11 & 313 & 10 & 15.650 & 172 \\
& & & & & Economia anual & 1.393 \\
\hline
\end{tabular}

Fonte: elaborada pelas autoras.

Dessa forma, o consumo mensal da empresa analisada, que utiliza lâmpadas incandescentes de 100w poderia substituí-las por lâmpadas de LED de $11 \mathrm{w}$, sem perda na qualidade da iluminação, com um ganho de $89 \%$ no consumo anual.

\subsection{POTENCIAL REDUÇÃO DE CUSTOS COM A TROCA DAS LÂMPADAS}

Considerando que as lâmpadas incandescentes comuns têm duração de 750 a 1.000 horas, enquanto as lâmpadas de LEDs duram até mais de 50.000 horas (BLEY, 2012), a substituição tem efeito financeiro imediato, na medida em que, de acordo com estudos do setor de iluminação, o segundo tipo é 90\% mais eficiente energeticamente quando comparado com o primeiro, conforme a Advanced Optronic Devices (BRASIL) S/A (2015).

A tabela 8 a seguir apresenta a potencial redução de energia elétrica com a substituição, utilizando o valor da tarifa residencial aprovada pela para a empresa ELETROPAULO, fornecedora no Estado de São Paulo:

TABELA 8. Potencial redução (em reais) no consumo de energia elétrica com a substituição das lâmpadas incandescentes por lâmpadas de LED.

\begin{tabular}{|c|c|c|c|}
\hline Tipo de lâmpada & $\begin{array}{c}\mathbf{k W h} / \text { ano } \\
\mathbf{F}=\mathrm{B} * \mathbf{E}\end{array}$ & $\begin{array}{c}\mathrm{R} \$ / \mathbf{k W h} \\
\mathrm{G}\end{array}$ & $\begin{array}{l}\text { RS total } \\
H=F * G\end{array}$ \\
\hline Incandescente & 1.565 & $\mathrm{R} \$ 0,4361$ & $\mathrm{R} \$ 682,51$ \\
\hline LEDS & 172 & $\mathrm{R} \$ 0,4361$ & $\mathrm{R} \$ 75,08$ \\
\hline Economia anual & 1.393 & - & $\mathrm{R} \$ 607,44$ \\
\hline
\end{tabular}

Fonte: elaborada pelas autoras. 


\subsection{DEPRECIAÇÃO DO INVESTIMENTO}

Levando-se em conta o preço médio no mercado em 2015 dos dois modelos, o investimento exigiria um montante de $\mathrm{R} \$ 100,00$ para a troca das 5 lâmpadas conforme observado na tabela 9.

TABELA 9. Investimento necessário para substituição de lâmpadas incandescentes por LED.

\begin{tabular}{cccccc}
\hline Tipo de lâmpada & $\begin{array}{c}\text { Durabilidade } \\
\text { (hs) }\end{array}$ & \multicolumn{3}{c}{ Custo médio } & Depreciação/hora \\
\cline { 3 - 5 } & 1.000 & $\mathrm{R} \$ 3,00$ & Quantidade & R\$ total & \\
\hline Incandescente & 50.000 & $\mathrm{R} \$ 20,00$ & 5 & $\mathrm{R} \$ 15,00$ & $\mathrm{R} \$ 0,015$ \\
\hline LEDS & $98 \%$ & $85 \%$ & $0 \%$ & $\mathrm{R} \$ 100,00$ & $\mathrm{R} \$ 0,002$ \\
\hline Variação & & & & &
\end{tabular}

Fonte: elaborada pelas autoras.

No entanto, ao ponderar a durabilidade das mesmas conforme tabela anterior, observa-se que a depreciação/hora apresenta um benefício de 650\%; assim, o investimento na troca das lâmpadas incadescentes por LEDs se pagaria em 1,94 dias.

Saliente-se que a empresa analisada necessitaria trocar, ao longo do tempo, as lâmpadas utilizadas, na medida em que, de acordo com a legislação vigente, a comercialização de lâmpadas incandescentes de 100W, 150W e $200 \mathrm{~W}$ está proibida desde 2010 e, a partir de julho de 2015 a proibição foi estendida às de $60 \mathrm{w}$.

\subsection{AVALIAÇÃO DA REDUÇÃO DE CO2}

O setor energético é o maior responsável pelo aumento da emissão de GEE no mundo, entretanto, no Brasil, devido à grande presença de fontes de energia renováveis na matriz energética o impacto é menor. Apesar disso, fatores como o ritmo de crescimento da economia e a expansão do consumo de energia terão papel fundamental no volume das emissões de $\mathrm{CO}_{2}$ e em projeções de cenários futuros, está prevista a emissões de cerca de 970 milhões de toneladas de $\mathrm{CO}_{2}$ no ano de 2030 se não houver intervenção (PIRES \& HOLTZ, 2012).

No empreendimento avaliado, o total de emissões em 2013 foi $1.259 .874 \mathrm{kgCO} 2 \mathrm{e} / \mathrm{kWh}$ em função do consumo de energia elétrica, onde a iluminação (5 lâmpadas incandescentes) corresponde a 13\%. Sua substituição por LED permitiria uma redução de $11,7 \%$ nas emissões totais de energia elétrica do estabelecimento a 
partir da mudança, o que consiste em mais de 50\% da meta da PEMC para 2020 (redução de 20\%).

\subsection{AVALIAÇÃO FINAL DO ESTUDO}

O cenário econômico atual acarreta na necessidade da redefinição de atitudes e administração financeira para manter a competitividade. A preocupação coletiva com o meio ambiente e a saúde e o bem estar traz a necessidade de associar a marca aos princípios da sustentabilidade e, está diretamente ligado à percepção do cliente e pode ser um diferencial na escolha do prestador de serviço. A redução de custos pode ser considerado como "financiamento a longo prazo para sustentar investimentos e atividades do dia a dia" (ROSS, WESTERFELD E JORDAN, 1998)

Os resultados do estudo apresentam, como principais elementos de avaliação, na substituição das lâmpadas incandescentes de 100w por lâmpadas de LED de $11 \mathrm{w}$ :

- redução de custos - manutenção da qualidade da iluminação com ganho de $89 \%$ no consumo anual;

- $\quad$ ganho monetário anual - de $\mathrm{R} \$ 106,50$ por lâmpada no primeiro ano e $R \$ 136,50$ nos seguintes, na medida em que o investimento é de $R \$ 20,00$, segundo preços médios de mercado e o consumo é de R \$682,51/ano com as cinco lâmpadas incandescentes, contra R \$75,08 com as lâmpadas de LED.

- Depreciação do investimento - considerando o maior tempo de utilização das lâmpadas LED (50.000 horas) em comparação com as incandescentes (1.000 horas), há um ganho de $650 \%$, na medida em que o custo da depreciação passa de $\mathrm{R} \$ 0,015$ para $\mathrm{R} \$ 0,002$ por hora.

- Melhoria no tempo de troca das lâmpadas - a troca das lâmpadas, embora não exija habilidade técnica, impõe o uso de escadas e tempo para compra e substituição, sendo fatores nem sempre imediatamente disponíveis, podendo implicar na avaliação negativa do serviço prestado em razão da iluminação inadequada.

- Redução dos níveis de CO2 - Se as lâmpadas incandescentes de 100W fossem substituídas por lâmpadas de LED de $11 \mathrm{~W}$, sem perda na qualidade da iluminação, o ganho de $89 \%$ no consumo anual poderia se refletir na redução de $11,7 \%$ nas emissões totais de energia elétrica do estabelecimento a partir da mudança. Com essa intervenção parece viável atingir a meta da PEMC e

REMIPE- Revista de Micro e Pequenas Empresas e Empreendedorismo da Fatec Osasco 
Os resultados indicam que, se demonstrados os benefícios financeiros para os empreendedores desse tipo de negócio, há alto potencial de interesse na substituição e, além da contribuição para a continuidade do negócio, se apresenta um importante elemento para a consciência ambiental e redução do consumo de recursos naturais energia elétrica - nesse segmento.

\section{CONSIDERAÇÕES FINAIS}

A possibilidade de redução do uso de recursos naturais tem sido um dilema na sociedade contemporânea, marcada pelo consumo desenfreado e; em especial o estabelecimento de padrões de beleza no capitalismo, construídos em torno de imagem pessoal ilusória, tornou os estabelecimentos de prestação de serviços nessa área - salões de beleza - um negócio de fácil implementação por pequenos empreendedores.

No entanto, para esse perfil empreendedor, o custo inicial, de instalação do negócio, concentra-se na obtenção de equipamentos, materiais e mão de obra, tornando a infraestrutura um elemento no qual se visa a menor aplicação de recursos. Nessa concepção, a iluminação, embora significativa do ponto de vista do cliente, na percepção dos resultados do serviço prestado, é pouco valorizado pelo empresário, que busca reduzir o investimento inicial com base em um fluxo de caixa imediato; assim, normalmente opta pelo tipo de iluminação mais barato - lâmpadas incandescentes.

Este estudo visou identificar os benefícios financeiros para o empreendedor do segmento de serviços de beleza, pela substituição de lâmpadas incandescentes por outras de maior eficiência energética (LEDs. Os resultados demonstraram que a recompensa financeira advinda de ações de troca das lâmpadas incandescentes por LEDs podem, além de contribuir para a rentabilidade financeira das micro e pequenas empresas, se apresenta com alto grau de contribuição para a sustentabilidade ambiental do planeta.

Conclui-se que a divulgação do resultados deste estudo e e de outros similares aos empreendedores em estágio inicial nesse segmento poderia contribuir significativamente para a redução do consumo de recursos naturais nos salões de beleza.

REMIPE- Revista de Micro e Pequenas Empresas e Empreendedorismo da Fatec Osasco 
Estudos futuros serão direcionados para a análise de outras potenciais contribuições para as micro e pequenas empresas que atuam no segmento de beleza salão de cabeleireiros - e o estabelecimento de propostas capazes de ampliar sua competitividade e melhorar a eficiência energética dos recursos utilizados nesse tipo de empreeendimento.

\section{REFERÊNCIAS}

ADVANCED OPTRONIC DEVICES (BRASIL) S/A. LED vs Fluorescente Compacta vs Incandescentes. Disponível em: http://www.aodbrazil.com/aod/portugues/impresa/catalogos/LED_CFL_LampadasIncandescentes.pdf Acesso em: 30 out 2015.

AGÊNCIA BRASIL. Custo da energia elétrica aumenta $60 \%$ em 12 meses. Disponível em: <http://agenciabrasil.ebc.com.br/economia/noticia/2015-04/custo-daenergia-eletrica-aumenta-60-em-12-meses $>$ Acesso em: 20 set. 2015.

ANEEL - AGÊNCIA NACIONAL DE ENERGIA ELÉTRICA. Conheça as Tarifas da Classe de Consumo Residencial de uma Concessionária. Disponível em $<$ http://www.aneel.gov.br/aplicacoes/tarifaAplicada/index.cfm $>$ Acesso em: 10 Out.2015.

ASSOCIAÇÃO BRASILEIRA DA INDÚSTRIA DE HIGIENE PESSOAL, PERFUMARIA E COSMÉTICOS - ABIHPEC. Panorama do Setor 2015. Disponível em: $<$ https://www.abihpec.org.br/2015/04/panorama-do-setor-2015/>. Acesso em 30. Set 2015

ANDRADE, A.A.; SOUZA, A.F.M.; SOUZA, J.M.T.; SILVA, K.N.M. Propostas De Melhoria Segunda Ótica Do Sistema De Gestão Ambiental: O Caso De Um Salão De Beleza Norteriograndense. Anais... IX CONGRESSO NACIONAL DE EXCELÊNCIA EM GESTÃO 20, 21 e 22 de junho de 2013. Disponível em $<\underline{\text { http://www.excelenciaemgestao.org/Portals/2/documents/cneg9/anais/T13 } 0600 \quad 3473}$ . $>$ pdf.

ATLAS DO DESENVOLVIMENTO HUMANO NO BRASIL. $<$ http://www.atlasbrasil.org.br/2013/pt/ranking > Acesso em: 20 set. 2015.

BARBIERI, J. C. Gestão ambiental empresarial - Conceitos, modelos e instrumentos. São Paulo: Saraiva, 2007.

BLESSA, R. Merchandising no ponto de venda. 4a. Ed. São Paulo: Atlas, 2006.

BLEY, F.B. LEDs versus Lâmpadas Convencionais Viabilizando a troca. Goiânia: IPOG, 2012. Revista on line Especialize. Maio/2012. Disponível em 
$<$ http://www.ipog.edu.br/download-arquivo-site.sp?arquivo=leds-versus-lampadasconvencionais-1443176.pdf. $>$ Acesso em 30.Set 2015

BRITISH STANDARDS INSTITUTION - BSI. Guide to PAS 2050: How to assess the carbon footprint of goods and services. $2^{\mathrm{a}}$ ed. Londres: Ed. BSI. 2011.

BRASIL - MINISTÉRIO DA CIÊNCIA, TECNOLOGIA E INOVAÇÃO. 16.1

Programa Nacional de Mudanças Climáticas. Disponível em:

$<$ http://www.mct.gov.br/index.php/content/view/77650.html $>$ Acesso em: 01 out. 2015.

BRASIL - PORTAL BRASIL. Pequenas empresas buscam consumo menor de energia. Disponível em: $\quad \underline{\text { http://www.brasil.gov.br/economia-e- }}$ emprego/2015/06/pequenas-empresas-buscam-consumo-menor-de-energia $>$ Acesso em 7 ago. 2015

EMPRESA DE PESQUISA ENERGÉTICA - EPE. Anuário estatístico de energia elétrica 2013. Rio de Janeiro, 2014. Disponível em: $<$ http://www.epe.gov.br/AnuarioEstatisticodeEnergiaEletrica/Anu\%C3\%A1rio\%20Esta t \%C3\%ADstico $\% 20 \mathrm{de} \% 20$ Energia $\% 20 \mathrm{El} \% \mathrm{C} 3 \%$ A 9 trica\%202014.pdf $>$. Acesso em: 13 out. 2015.

EMPRESA DE PESQUISA ENERGÉTICA - EPE - Anuário Estatístico de Energia Elétrica. Brasília: Empresa de Pesquisa Energética, 2015. Disponível em

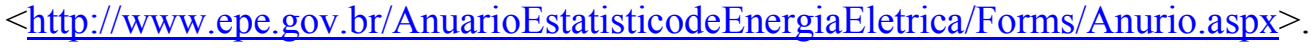
Acesso em 02 Out.2015.

GREEN NATION. Sustentabilidade em todos os sentidos. Fonte: $<$ http://www.greennation.com.br/pt/dica/163/Equipe-GreenNation/Sal-o-de-Beleza> Acesso em: 12 set. 2015.

GLOBAL ENTREPRENEURSHIP MONITOR - GEM. Empreeendedorismo no Brasil. Resumo Executivo. Global Entrepreneurship Monitor (GEM). Disponível em $<$ http://www.ibqp.org.br/upload/tiny mce/Download/GEM 2014 Relatorio Executivo Brasil.pdf. Acesso em 03 Out.2015>. Acesso em: 7 set. 2015.

IBGE - INSTITUTO BRASILEIRO DE GEOGRAFIA E ESTATÍSTICA. Cidades @ Disponível em:

$<$ http://www.cidades.ibge.gov.br/xtras/temas.php? codmun=354870\&idtema $=118 \&$ searc $\mathrm{h}=$ sao-paulo $\% 7$ Csao-bernardo-do-campo $\% 7 \mathrm{C} \% \mathrm{C} 3 \% 8 \mathrm{Dndice}$-de-desarrollo-humanomunicipal-idhm-\&lang> Acesso em: 10 set. 2015.

. Pesquisa de Orçamento Familiar - POF - 2008-2009. Rio de Janeiro:

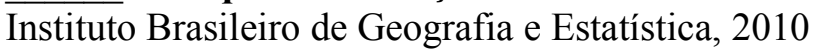

INSTITUTO ETHOS. Criando valor: O business case para sustentabilidade em mercados emergentes. São Paulo: Instituto Ethos, 2003. Disponível em: 
$<$ http://www.uniethos.org.br/_Uniethos/Documents/folheto_ifc.pdf. $>$. Acesso em: 15 abr. 2010 .

JACOBI, P. R. et al. Mudanças climáticas globais: a resposta da educação. Rev. Bras. Educ., Rio de Janeiro , v. 16, n. 46, p. 135-148, Apr. 2011. Disponível em: $<$ http://www.scielo.br/scielo.php?script=sci arttext\&pid=S1413-

24782011000100008\&lng=en\&nrm=iso $>$. Acesso em: 30 out. 2015.

LOPES, I.V. (Coord.). O mecanismo de desenvolvimento limpo: guia de orientação. Rio de Janeiro: Fundação Getulio Vargas, 2002.

MENDES, R. Excelência não é um feito, mas um hábito. Curitiba: AZ Soluções. s.d. Disponível $\quad$ em: $<$ http://www.azsolucoes.com.br/index.php/colunistas/roberto/151excelencia-nao-e-um-feito-mas-um-habito $>$. Acesso em 12 Out.2015.

MICHEL, M.H. Metodologia e pesquisa científica em ciências sociais. São Paulo, SP: Atlas. 2005.

MIRANDA, C.M. A construção do ideal de beleza feminina em comerciais de televisão. I Encontro de História da Mídia da Região Norte Universidade Federal do Tocantins - Palmas - outubro de 2010. Disponível em: $<$ http://www.ufrgs.br/alcar/noticias-dos-

nucleos/artigos/A\%20CONSTRUCaO\%20DO\%20IDEAL\%20DE\%20BELEZA \%20FE MININA\%20EM\%20COMERCIAIS\%20DE\%20TELEVISaO.pdf $>$. Acesso em 29 Set. 2015.

O POVO ON LINE. Preço da energia segue tendência de alta. Disponível em: $<\underline{\text { http://www.opovo.com.br/app/opovo/economia/2015/05/19/noticiasjornaleconomi }}$ a,3440122/preco-da-energia-segue-tendencia-de-alta.shtml $>$. Acesso em: 02 ago 2015.

PIRES, A.; HOLTZ, A. Sistema Elétrico Brasileiro: Agenda Ambiental. Rio de Janeiro: CBIE - CENTRO BRASILEIRO DE INFRAESTRUTURA Março 2012. Disponível

em: $<$ http://www.cbie.com.br/arquivos/agenda\%20ambiental $\% 20 v e r s \% \mathrm{C} 3 \% \mathrm{~A} 3 \mathrm{o} \% 20 \mathrm{fin}$ al\%20revisada.pdf $>$. Acesso em: 29 out. 2015.

PROGRAMA DAS NAÇÕES UNIDAS PARA O DESENVOLVIMENTO - PNUD. Atlas do Desenvolvimento Humano no Brasil 2013. Disponível em: $<$ http://www.pnud.org.br/IDH/Atlas2013.aspx?indiceAccordion=1\&li=li Atlas2013 $>$.

Acesso em: 14 set. 2015.

POPERMAYER, C. B. Sistemas de gestão de custos: dificuldades na implantação. Rev. FAE, Curitiba, v.2, n.3, set/dez/1999.

QUEIROZ NETO, L.S. Boa iluminação faz toda a diferença! Campinas, 2010.

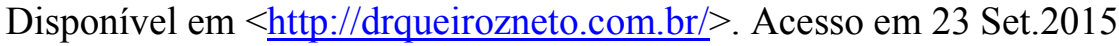


RECKWITZ, A. Toward a theory of social practices: A development in culturalis theorizing. European Jornal of Social Theory. v. 5, n. 2, p. 243-263, May-2002.

RIBAS, R. E. B.; CALEIRO, M.M.. Padrões estéticos e globalização: a sociedade pósmoderna frente à ditadura da beleza. Intercom - Sociedade Brasileira de Estudos Interdisciplinares da Comunicação. Anais... XVII Congresso de Ciências da Comunicação na Região Sudeste - Ouro Preto - MG - 28 a 30/06/2012. Disponível em: $<$ http://www.intercom.org.br/papers/regionais/sudeste2012/resumos/R33-1567-1.pdf $>$.

Acesso em 12 Out.2015

ROSS, S.A.; WESTERFIEL, R.; JORDAN, B. D. Princípios de administração financeira -essentials of corporate finance. São Paulo. Atlas. 1998

SANTOS, A.R.; COSTA, J.I.P.; CARDOSO, O.R.C.. A importância dos cenários para conquista da qualidade em serviços. Anais... XXVIII ENCONTRO NACIONAL DE ENGENHARIA DE PRODUÇÃO. Rio de Janeiro, RJ, Brasil, 13 a 16 de outubro de 2008.

Disponível em: $<$ http://www.abepro.org.br/biblioteca/enegep2008 TN_STP $070 \quad 502$ 10987.pdf $>$. Acesso em: 15 Out.2015.

SEBRAE. Projeto leva sustentabilidade a salões de beleza. Disponível em $<$ http://www.rn.sebrae.com.br/noticia/projeto-leva-sustentabilidade-a-saloes-de-beleza $>$ Acesso em: 30 out 2015.

WARDE, A. Consumption and theories of practice. Journal of Consumer Culture, v.5, n.2, p. 131-153, 2005. 